\title{
A clinical review of recent findings in the epidemiology of inflammatory bowel disease
}

This article was published in the following Dove Press journal:

Clinical Epidemiology

24 July 2013

Number of times this article has been viewed

\author{
Alexis Ponder \\ Millie D Long \\ Department of Medicine, University \\ of North Carolina, Chapel Hill, \\ NC, USA
}

\begin{abstract}
Inflammatory bowel diseases (IBD), including both Crohn's disease and ulcerative colitis, are disorders of chronic inflammation of the gastrointestinal tract marked by episodes of relapse and remission. Over the past several decades, advances have been made in understanding the epidemiology of IBD. The incidence and prevalence of both Crohn's disease and ulcerative colitis have been increasing worldwide across pediatric and adult populations. As IBD is thought to be related to a combination of individual genetic susceptibility, environmental triggers, and alterations in the gut microbiome that stimulate an inflammatory response, understanding the potentially modifiable environmental risk factors associated with the development or the course of IBD could impact disease rates or management in the future. Current hypotheses as to the development of IBD are reviewed, as are a host of environmental cofactors that have been investigated as both protective and inciting factors for IBD onset. Such environmental factors include breast feeding, gastrointestinal infections, urban versus rural lifestyle, medication exposures, stress, smoking, and diet. The role of these factors in disease course is also reviewed. Looking forward, there is still much to be learned about the etiology of IBD and how specific environmental exposures intimately impact the development of disease and also the potential for relapse.
\end{abstract}

Keywords: clinical epidemiology, inflammatory bowel disease, environmental risk factors

\section{Introduction}

Inflammatory bowel diseases (IBD) are chronic inflammatory disorders of the gastrointestinal tract marked by episodes of relapse and remission. There are two identified subtypes of the disease, ulcerative colitis (UC) and Crohn's Disease (CD), which differ in patterns of involvement. Though varying in clinical presentation, the two subtypes share a presumed etiology of genetic predisposition, environmental risk factors or exposures, and alterations of the gut microbiome that contributes to the manifestation of disease. Ongoing changes in environmental factors, including infections, diet, lifestyle factors, and medication use have contributed to shifts in the global prevalence of the disease.

\section{Epidemiology of IBD}

Currently, the annual incidence of CD is highest in North America (20.2 per 100,000, per person years); whereas the annual incidence of UC is highest in Europe (24.3 per 100,000 per person years). The prevalence of both UC and CD are highest in Europe (505 and 322, per 100,000 per person years respectively). ${ }^{1}$ A much lower prevalence is found in other areas of the world. ${ }^{1}$ However, IBD appears to be emerging in such
Correspondence: Millie D Long Campus Box 7080, University of North Carolina at Chapel Hill, Chapel Hill, NC 27599-7080, USA

$\mathrm{Tel}+\mathrm{I} 9198435795$

Fax + I 9199666842

Emailmillie_long@med.unc.edu 
areas as the People's Republic of China, South Korea, India, Lebanon, Iran, Thailand, the French West Indies, and North Africa, correlating with industrialization and westernization of these areas. ${ }^{2}$ Prevalence of IBD is affected by both incidence (new diagnoses) and duration of disease. As IBD is a chronic disabling disorder without high mortality, prevalence rates may now be increasing due to earlier diagnoses and potentially to longer duration of disease. The more recent findings in geographic trends of IBD may argue against the previously observed north-south gradient described in Europe, the US, Scotland, and France. For example, there are now higher incidence rates of IBD in countries such as Australia ${ }^{3}$ and New Zealand. ${ }^{4}$ The incidence of IBD has continued to rise in other prior low incidence areas, such as Asia and the developing world. As IBD emerges in developing countries, UC appears first, followed by a rising trend in CD is observed. ${ }^{5}$ This pattern is being seen currently in Asia. ${ }^{6}$ These data support the argument that lifestyle and environmental factors are important cofactors in the etiology of IBD. Importantly, there are only limited data on the epidemiology of IBD to date in under developed countries. More accurate means of determining incidence and prevalence in these areas are needed.

Pediatric IBD demonstrates a different pattern, with CD predominating over UC. In a recent population based study from Sweden, the incidence of CD was estimated to be (95\% confidence interval [CI] 7.5-11.2) per 100,000 per person years. The incidence of UC in children over the same time period was 2.8 (95\% CI 1.9-4.0) per 100,000 per person years. ${ }^{7}$ These rates are somewhat higher than those reported in other pediatric studies, although similar to those reported in modern studies from Canada, ${ }^{3,8,9}$ Norway, ${ }^{10}$ and Finland. ${ }^{11}$ In a recent systematic review of international trends in pediatric IBD incidence, over $60 \%$ of studies reported a rising incidence of $\mathrm{CD}$ and $20 \%$ reported a rising incidence of UC. This increasing incidence occurred in both developed and developing nations; however, admittedly, most countries lacked accurate estimates. ${ }^{3}$

Interestingly, geographic location plays a convincing role in IBD development. For example, studies of emigrants have demonstrated that migration from a lower prevalence area of IBD to a higher prevalence area increases a person's associated risk. In a study of children who migrated from South Asia to British Columbia (BC), migrants had an even higher incidence of IBD than the rest of the $\mathrm{BC}$ pediatric population. ${ }^{12}$ Additionally, there was a different pattern of phenotypic expression, male predominance, and more extensive colonic disease among immigrants. This suggests a potential effect of migration, and environmental and lifestyle changes not only on IBD development, but potentially on phenotype and course of disease. In a separate study of Indian emigrants who moved to Leicestershire, incidence rates of UC were comparable to those in their new environment. ${ }^{13}$ Among those emigrating from low to high prevalence countries, first generation children seem to be at a higher risk for IBD in their new environments. Age at time of migration also appears to be important, as those raised in the adoptive country or those who migrated during childhood have the greatest risk of developing IBD. ${ }^{5}$ This pattern of increased risk associated with emigration has been replicated in other nationalities as well. For example, in a study of emigrants from Spain to other countries, there was an increased risk of IBD with emigration to westernized European countries (odds ratio [OR] 1.91, 95\% CI 1.07-3.47), but not to Latin America (OR 1.48, 95\% CI 0.67-3.27). ${ }^{14}$ Certainly, the increased rates of IBD development in emigrants provide etiologic clues as to the important environmental cofactors necessary for disease occurrence.

Little difference has been found in rates of IBD with gender, with relatively equal gender distributions across multiple studies. However, in a study of patients in Ontario from 1994 to 2005, a predominance of male patients with CD was identified in younger age groups (5-9 years and 10-14 years), but the incidence was balanced between males and females by $15-17$ years of age. ${ }^{15}$ With regards to age, the incidence of IBD has been found to be the highest between the second and fourth decade of life, with a median age of onset slightly higher for UC when compared to CD. Earlier studies $^{16-22}$ show a bimodal distribution of IBD incidence, with the highest incidence between ages 20 to 39 years, and another peak occurring at age 60 . This second peak has not been replicated in a more recent study. ${ }^{23}$ In areas of emerging incidence of IBD, such as Asia, there is a male predominance for $\mathrm{CD}$, but a more equal gender distribution for UC. The age of diagnosis in Asia is slightly higher than that in European countries and there is rarely a second incidence peak. ${ }^{6}$

\section{Genetic-environment interactions Genetics}

Recently, there has been a great increase in the understanding of the genetic component of IBD etiology. Genome wide association studies have identified over 160 susceptibility loci/genes that are significantly associated with IBD. ${ }^{24,25}$ For CD, gene discoveries have focused on defective processing of intracellular bacteria, autophagy, and innate immunity. For UC, the focus has been on barrier function. 
There is also a suggestion of overlap of some susceptibility loci with other immune related diseases. ${ }^{25}$ In a study published in 2003 that focused on familial aggregation of IBD, the concordance level was only $50 \%$ for CD and $19 \%$ for UC in monozygotic twins. ${ }^{26,27}$ This provides evidence that more than genetics is needed for IBD development. Interestingly, in a recent extension of the Swedish twin registry ${ }^{28}$ with extended observation time, an even lesser rate of pair concordance was found for monozygotic twins (27\% for $\mathrm{CD}$ and $15 \%$ for UC). ${ }^{28}$ By comparing concordant and discordant twin pairs with $\mathrm{CD}$, the authors found a trend for phenotypic differences, suggesting that pathophysiological differences may be associated with separate phenotypes of $\mathrm{CD} .{ }^{28}$ Sharing a living environment increases the incidence of IBD, as seen in new diagnoses of IBD in family members and spouses of individuals with IBD sharing living space. ${ }^{29,30}$ Birth order also influences disease status. As adjacent order of birth estimates environmental sharing, this suggests that environmental factors contribute to the observed familial aggregations of IBD. ${ }^{22}$ Differences between CD and UC are thought to be not only due to genetic predisposition, but also be partially due to the impact of environmental exposures and triggers subsequently affecting the host's immunity.

\section{Gastrointestinal microbiota}

The enteric microbiota are now accepted as a central etiologic factor in the pathogenesis of IBD. ${ }^{25,31}$ It is thought that the first year of life is a critical time period for development of an individual's microbiome and potentially helps to establish whether maintenance of homeostasis versus development of inflammation will occur. Importantly, bacteria mediated epigenetic effects on the mucosal immune system in early life have been shown to affect the development of immunologically mediated disease in adulthood. ${ }^{32}$ Recent changes in technology have allowed for a greater understanding of the composition and community structure of the intestinal microbiota. Researchers have determined how enteric bacterial species and their metabolic products interact within the host. Immunologic properties of individual species and groups of bacteria have been described. ${ }^{33,34}$ Specific viral or bacterial commensal microbes appear to selectively interact with host genes to influence intestinal inflammation. Epidemiology has aided in the discovery of the microbiome as an important factor in IBD development, as studies of early life antibiotic exposure (which alters the intestinal microbiome) have shown increased risk for development of CD later in life. ${ }^{35}$

\section{Hygiene hypothesis of IBD development}

A key principle to understanding the genetic-environmental interactions associated with IBD development is the hygiene hypothesis. In essence, this hypothesis proposes that "cleaner" environments with lower rates of communicable diseases are associated with increased rates of IBD development, and that the converse is also true, less hygienic environments play a protective role. Protective factors that have been proposed under this hypothesis include lower rates of antibiotic use, increased numbers of pets and livestock, larger family sizes, and increased exposure to enteric pathogens (specifically Helicobacter pylori $[H$. pylori] and helminths). ${ }^{36}$ There is an increased risk of IBD development in countries with lower rates of enteric pathogens and where there is greater access to hot water and other sanitization resources. In general, in developing countries, where there are more infectious exposures in childhood, there are lower rates of allergic disorders. Not all studies have been consistent in whether these "hygiene factors" are associated with IBD development. ${ }^{37}$ Some of these differences may be related to the retrospective nature of prior case control studies, and potential for biases in recall and how controls are selected. Only a further understanding of how each environmental exposure is associated with IBD development will impact occurrence of IBD in the future.

\section{Environmental exposures and IBD Breast feeding}

There is conflict as to whether breast feeding increases the risk, or encompasses a protective role, for the development of IBD by alteration of the gut microbiota of breast fed infants. In a population based case control study of 222 incident cases of CD occurring prior to age 17 , breast feeding was a significant risk factor for CD (OR 2.1, 95\% CI 1.3-3.4).$^{38}$ A meta-analysis of 14 case control studies found that breast feeding had a protective effect on the development of UC (OR 0.61, 95\% CI 0.44-0.84), but not on CD. ${ }^{39}$ A second systematic review and meta-analysis published in also found a significant protective effect (OR 0.69, 95\% CI 0.51-0.94) for the development of early onset IBD overall. ${ }^{40}$ However, the findings did not reach statistical significance for $\mathrm{CD}$ and UC separately. ${ }^{40}$ Another study has shown no effect of breast feeding on IBD development. ${ }^{41}$ Interestingly, there may be a dose-response effect for breast feeding, with a recent case control study demonstrating a protective effect only after a duration of 3 months or more. ${ }^{42}$ A separate recent study found a nonsignificant protective effect (OR 0.50, 95\% CI $0.23-1.11)$ for a breast feeding duration of $>6$ months. ${ }^{43}$ 
This may be one factor contributing to the conflicting data in the literature, as some studies did not take duration of breast feeding into account. Limitations to prior studies include the potential for recall bias and that studies primarily utilized retrospective data collection. The potential mechanism of action of breast feeding impacting development of IBD is thought to be related to changes in the gut flora of breast fed infants. In breast fed infants, there are higher concentrations of bifidobacteria and fewer anaerobic bacteria in feces when compared to bottle fed infants. ${ }^{44}$ It is thought that fecal flora can continue to change up until 2 years of age, demonstrating the potential need for a longer duration of breast feeding to impact a child's risk of IBD development. ${ }^{45}$

\section{Infectious exposures}

Several infectious agents have been suspected to affect the development of IBD, whether in a protective or inciting role, including causes of acute bacterial gastroenteritis, $H$. pylori, and helminth exposure. These infectious factors may alter the gut microbiota or may have a specific immunomodulatory role in development of IBD.

\section{Bacterial gastroenteritis}

In a population based study from two Danish counties comparing persons exposed to salmonella and Campylobacter gastroenteritis identified in lab registries to matched unexposed individuals, the hazard ratio (HR) of first time diagnosis of IBD of those who were exposed compared to those who were unexposed was 2.9 (95\% CI 2.2-3.9) for the whole 7.5 year observation period and 1.9 (95\% CI 1.4-2.6) for the first year, after exposure was excluded. ${ }^{46}$ In a separate study in the military population, a prior episode of infectious gastroenteritis was associated with an increased risk of IBD, even after excluding episodes in the 6 months prior to IBD diagnosis (OR 1.40, 95\% CI 1.19-1.66). ${ }^{47}$ It is understood, however, that those with IBD are more likely to undergo hospitalizations and diagnostic testing which may isolate bacterial infections more frequently than in the population without IBD. Additionally, the risks associated with a bacterial gastroenteritis may also be influenced by antibiotics that were prescribed for treatment of the infection. Alterations in the gut microbiota that occur may be related to the antibiotic, which can then be attributed to the prior bacterial infection.

\section{H. pylori}

H. pylori has also been implicated in the development of autoimmune diseases including multiple sclerosis, systemic lupus erythematosus, asthma, and IBD. ${ }^{48,49} H$. pylori is a common chronic bacterial infection in humans that is often acquired in childhood in less developed countries. Chronic colonization with $H$. pylori may also be associated with social class and other protective factors involved in the hygiene hypothesis. In a meta-analysis of 23 studies, $H$. pylori infection was inversely associated with IBD, more so for CD than for UC. ${ }^{48}$ Overall, $27.1 \%$ of IBD patients had evidence of prior infection with $H$. pylori in comparison to $40.9 \%$ of patients in the control group. The meta-analysis described a number of important flaws in the literature which caused difficulty in aggregating the individual study findings. For example, there was evidence of publication bias, heterogeneity among studies, and differing modalities for diagnosis of H. pylori infection. In a recent study using surgical pathology reports, the presence of $H$. pylori was inversely associated with IBD, with an adjusted OR of 0.48 (95\% CI $0.27-0.79)$ for CD and an adjusted OR of 0.59 (95\% CI 0.39-0.84) for UC. ${ }^{50}$ Experimentally, researchers have shown that the $H$. pylori genome has immunoregulatory properties and can downregulate inflammatory responses through interaction with mucosal dendritic cells. ${ }^{51}$ While $H$. pylori may play an as of yet undefined role in the development of IBD, there are no data on the role of $H$. pylori in improving or exacerbating disease activity.

\section{Helminths}

Helminths are complex multicellular organisms that have the ability to induce immune host regulatory cells that suppress inflammation. ${ }^{52}$ Helminths have, therefore, been investigated as having a potentially protective effect in IBD development due to the aforementioned geographical differences in IBD incidence, with prevalence of IBD inversely related to helminth burden. Helminths are divided into three main groups: nematodes (round worms), trematodes (flukes), and cestodes (tape worms). Each group may have a distinct effect on immune modulation, and potentially on development or treatment of immune mediated disorders. ${ }^{52}$ Helminths are also thought to have an immunoregulatory role within the intestinal flora. ${ }^{53}$ In a recent case control study from South Africa, childhood exposure to helminths was protective against both CD and UC development (adjusted OR of 0.2 [95\% CI $0.1-0.4$ ] for CD and adjusted OR of 0.2 [95\% CI 0.1-0.6] for UC). ${ }^{54}$ Experimental data on helminths have also shown a protective effect on IBD development. In animal models of IBD, helminth colonization suppresses intestinal inflammation through multiple mechanisms including induction of innate and adaptive regulatory circuits. ${ }^{55,56}$ For example, in 
murine models of IBD, the helminth Heligmosomoides polygyrus bakeri prevents colitis by altering dendritic cell function. ${ }^{55}$ Interestingly, helminth exposure has also been shown to shift the composition of intestinal bacteria, ${ }^{56}$ which may then impact disease development or course. When Trichuris suis (T. suis), a whipworm, was used in a small open label study of CD, patients showed improvement in their disease activity and quality of life scores. ${ }^{57}$ Patients with UC also experienced beneficial effects of oral T. suis administration in a small randomized controlled trial. ${ }^{58}$ Whipworms are potentially a good candidate for clinical use as they do not migrate beyond the intestines or multiply within their host. They are also not transmitted from one human to another. Further trials of helminths in the treatment of both CD and $\mathrm{UC}$ are ongoing.

\section{Medications}

\section{Antibiotics}

Early and recurrent exposure to antibiotics has been associated with an increased risk of developing IBD. Published 2012, a retrospective cohort study of children 2 years of age or older from the UK compared the incidence rate of IBD in those who were and were not exposed to antianaerobic antibiotics. ${ }^{59}$ The incidence rate of IBD was higher in those exposed to antibiotics when compared to those who were not, where the incidence was 0.83 and 1.52 per 10,000 person years, respectively, for an $84 \%$ relative risk increase. Time of antibiotic exposure was also important, although exposure to antibiotics throughout childhood was associated with developing IBD, the relationship decreased with increasing age at exposure. Lastly, a dose-response effect existed, with receipt of more than two antibiotic courses being more highly associated with IBD development than receipt of one to two courses, with adjusted HR of 4.77 (95\% CI 2.13-10.68) versus 3.33 (95\% CI 1.69-6.58), respectively. ${ }^{59}$ In a nested case control study in Canada, antibiotic use within the first year of life was also associated with a significantly increased risk (almost three fold) of developing IBD, with a stronger risk for $\mathrm{CD} .{ }^{60} \mathrm{~A}$ separate case control study in Finland found an increased risk of pediatric $\mathrm{CD}$ associated with early antibiotic use, even with exclusion of prescriptions in the 6 months prior to diagnosis (OR 3.48, 95\% CI 1.57-7.34). ${ }^{61}$ There was no increased risk of UC associated with antibiotic use in this study.$^{61}$ Use of antibiotics may therefore be associated with disease development through a mechanism of alteration of the gut microbiome, or alternatively, patients with a genetic susceptibility to IBD may have increased susceptibility to childhood infections, thereby requiring more frequent antibiotic dosing. Interestingly, adults with newly diagnosed IBD are also more likely to have taken antibiotics in the 5 years prior to IBD diagnosis. There was a dose-dependent relationship between the number of antibiotic dispensations and the risk of IBD in an adult Canadian population. ${ }^{62}$ Whether there is a direct pathologic effect of antibiotics alone or in association with an immune response, those with greater access to antibiotics appear more likely to develop IBD.

\section{Oral Contraceptive Agents (OCPs)}

OCPs are a commonly used method to prevent pregnancy and is a common exposure for women of child bearing age. There has been much debate as to whether OCPs increase the incidence of IBD or lead to more frequent relapses in those already diagnosed. Following the trend of findings observed in previous studies, in a review ${ }^{63}$ of two large prospective cohorts of US women published in 2012, OCP use was associated with a modest risk of CD more so than UC. Specifically, when compared with never users of OCPs, the HR for CD was 2.82 (95\% CI 1.65-8.84) among currents users and 1.39 (95\% CI 1.05-1.85) among past users. ${ }^{63}$ Furthermore, it was found that the association between OCP use and UC was limited to women with a history of smoking, which suggests a multifaceted rather than isolated influence of estrogen and subsequent disease development. In a meta-analysis published in 2008 from the UK, a modest positive association for development of CD and UC with OCP use after controlling for smoking (pooled relative risk [RR] 1.46 for CD and 1.28 for UC) was found. ${ }^{64}$ Additionally, the risk for patients who stopped OCPs reverted back to that of the unexposed population. ${ }^{64}$ The proposed mechanism of action behind OCP use and development of IBD is thought to be related to estrogen-based immune enhancement and proliferation of macrophages, or possibly due to promotion of microvascular bowel ischemia and thrombosis. ${ }^{64}$ One prior study has shown an increased risk of relapse among patients with CD on OCPs (HR 3.0, 95\% CI 1.5-5.9), although it is unclear whether higher doses of estrogen may be involved in this risk, as data were from the 1990s in this study. ${ }^{65}$ A second study during the same time period showed no increase in risk of relapse in patients with CD on OCPs. ${ }^{66}$ Therefore, although evidence is limited, OCPs are not definitively associated with a significant risk of relapse of IBD in individuals with established disease. ${ }^{67}$

\section{Nonsteroidal anti-inflammatory agents (NSAIDs)}

NSAIDs are thought to influence IBD development via direct damage to the mucosa of the bowel or through reduction in 
prostaglandin production. ${ }^{6}$ NSAIDs have been associated with an increased risk for both CD and UC. In 2012, a prospective cohort study ${ }^{69}$ of women in the US revealed that frequent use of NSAIDs, but not aspirin, was associated with an increased absolute incidence of CD and UC. Specifically, when compared with nonusers, women who used NSAIDs at least 15 days per month had an increased risk for both CD and UC (absolute difference in age adjusted incidence of six cases per 100,000 person years [HR 1.59, 95\% CI 0.99-2.56] for CD and an absolute difference of seven cases per 100,000 person years [HR 1.87, 95\%CI 1.16-2.99] for UC). ${ }^{69}$ The same risk was not found with specific use of aspirin in this study. In a separate trial investigating the potential for relapse among individuals with established IBD, NSAID ingestion was associated with frequent and early clinical relapse. Within 9 days of ingestion, $17 \%-28 \%$ of patients on NSAID therapy relapsed. ${ }^{70}$ In this short-term study, selective inhibition of cyclooxygenase-2 was well tolerated without risk of relapse. In contrast, another study has not found NSAIDs to be associated with flares of established disease. ${ }^{71}$ More prospective data are needed on the role of NSAIDs in disease development and exacerbation.

\section{Vitamin D}

The role of vitamin D in IBD development and exacerbation is emerging. Patients with both previously diagnosed and new onset IBD have been found to be vitamin D deficient. This deficiency is thought to be related to reduced physical activity, reduced sunlight exposure, malnutrition, inadequate dietary intake, or lower bioavailability. It is also possible that vitamin $\mathrm{D}$ affects the immune system through T cells, B cells, and antigen-presenting cells, impacting disease development and/ or course. ${ }^{72}$ A study from a large prospective cohort of female nurses initiated in 1976 and 1989, respectively, revealed that women living in southern latitudes had a lower risk of CD (HR 0.48, 95\% CI 0.30-077) and UC (HR 0.62, 95\% CI 0.42-0.90) when compared to those residing in northern latitudes. ${ }^{73}$ This trend, consistent with the north-south gradient of disease that has been seen historically in the US and Europe, has been hypothesized to correlate with ultraviolet light exposure and ultimately vitamin D levels. In another study from this cohort, higher predicted plasma levels of 25-hydroxyvitamin D $(25(\mathrm{OH}) \mathrm{D})$ significantly reduced the risk for incident $\mathrm{CD}$ but did not significantly reduce the risk for UC in women. ${ }^{74}$ Specifically, women with a $25(\mathrm{OH}) \mathrm{D}$ level greater than $30 \mathrm{ng} / \mathrm{mL}$ had a significantly reduced risk of $\mathrm{CD}$ when compared to women with a predicted $25(\mathrm{OH})$ D level less than $20 \mathrm{ng} / \mathrm{mL}$ (HR 0.38, 95\% CI 0.15-0.97), and a nonsignificant decreased risk of UC (HR 0.57, 95\% CI 0.19-1.70). In a separate study evaluating the impact of vitamin $\mathrm{D}$ level on disease course, vitamin $\mathrm{D}$ deficiency was associated with lower health related quality of life and increased disease activity in $\mathrm{CD} .^{75}$

\section{Lifestyle exposures Socioeconomic factors}

Living in an urban setting has been associated with an increased risk for IBD through a series of studies conducted in the last six decades. In a systematic review published in 2012 , living in an urban setting was associated with an increased risk of both $\mathrm{UC}$ and $\mathrm{CD}$ (pooled Incidence rate ratio (IRR) 1.17 [95\% CI 1.03-1.32] for UC and pooled IRR 1.42 [95\% CI 1.26-1.60] for CD). ${ }^{76}$ In a Norwegian study, the incidence of IBD was higher in rural areas with a recent increase in socioeconomic status, when compared to urban areas with a stable high socioeconomic level. ${ }^{77}$ Several factors may be involved in these increased risks, including population density, education, lifestyle changes, and potentially, exposure to industrial agents. For example, in a database study of residents in the UK, it was found that ambient air pollution was not associated with IBD, but exposure to $\mathrm{SO}_{2}$ and $\mathrm{NO}_{2}$ may increase the risk of early onset $\mathrm{UC}$ and $\mathrm{CD}$, respectively. ${ }^{78} \mathrm{In}$ an ecological study, total air emissions of criteria pollutants were also significantly correlated with hospitalizations for adults with IBD. ${ }^{79}$ While causality cannot be concluded from a ecological study, these data lend support to the hypothesis that components of industrialization, such as pollution, may play a role in the development and course of IBD. In a study of German employees, factors such as working in the open air and physical exercise were protective against the development of IBD, while being exposed to artificial working conditions, including climate control mechanisms such as air conditioning, or extending and irregular shift working, increased the risk of IBD. ${ }^{80}$ These findings further argue that factors associated with an urban lifestyle influence one's risk of IBD. It is unclear whether the relationship occurs due to the environment itself or in combination with one's genetic predisposition to the disease.

\section{Smoking}

Smoking is the most widely and longest studied environmental exposure associated with IBD. To date, it has been observed that smoking has a varying impact on $\mathrm{CD}$ and UC, contributing to an increased risk for individuals with $\mathrm{CD}$ and a protective role in individuals with UC. In an early meta-analysis, current smoking (OR 2.0, 95\% CI 1.65-2.47) 
was shown to increase the risk for $\mathrm{CD}$, but paradoxically decreased the risk for UC (OR $0.41,95 \%$ CI $0.34-0.48) .{ }^{81}$ A more recent meta-analysis, using quality standards for meta-analysis reporting, found similar effects, with an increased risk for $\mathrm{CD}$ associated with current smoking (OR $1.76,95 \%$ CI 1.40-2.22) and an increased risk for UC with former smoking (OR 1.79, 95\% CI 1.37-2.34). Current smoking served a protective role in the development of UC (OR 0.58, 95\% CI 0.45-0.75). ${ }^{82}$ This protective role of smoking in UC remains until 2-5 years after cessation, after which increased risk develops. This risk may remain elevated for up to 20 years. ${ }^{83}$ The pathophysiology associated with the paradoxical effects of smoking on CD and UC is not well understood, but it is hypothesized that there are influences from nicotine and oxidative stress. ${ }^{84}$ Not only does smoking have an impact on the incidence of IBD, it also influences disease course by inciting relapses among those with CD. In a prospective cohort study ${ }^{85}$ published in 1999, the adjusted RR for disease relapse among current smokers with CD was 1.35 (95\% CI 1.03-1.76). This risk was increased in patients with previously inactive disease and in those who had no colonic lesions. The increased risk of disease relapse has became significant above a threshold of 15 cigarettes per day. In this study, former smokers behaved like nonsmokers and were noted not to have the observed increased risk. Additionally, smoking is associated with an increased risk of disease recurrence after surgery in CD ${ }^{85,86}$ Interestingly, the studies on smoking are not necessarily consistent across all ethnic groups, demonstrating the potential for interaction between smoking and other environmental or genetic factors to influence disease occurrence, course, or phenotype., ${ }^{2,87}$

\section{Diet}

As a large and variable environmental exposure, dietary factors may serve as risk or protective factors on IBD development. There are several proposed mechanisms of action for the visualized associations between IBD and dietary choices. These proposed mechanisms include a direct effect of dietary antigens, alteration of gut permeability, and the autoinflammatory response of the mucosa due to changes in the microbiota. ${ }^{88}$ In a survey of IBD patient opinion on the role of diet, a significant proportion of patients felt that dietary factors play a causative role in disease initiation $(15.6 \%)$ or in disease relapse $(57.8 \%) .{ }^{89 \mathrm{~s}}$ However, diet is difficult to study as it is a multifactorial exposure, and patients may alter dietary habits based on symptom onset prior to diagnoses or as a result of increased disease activity. Carbohydrates have been found to have a secondary rather than causal relationship with IBD when consumed in high concentrations. ${ }^{90}$ Fiber has also been studied for its potential anti-inflammatory role in the diet, and although there are data to suggest a protective role, the converse is also possible. In a cross-sectional study of dietary habits in patients with $\mathrm{CD}$ and compared to controls, the mean dietary fiber intake was $26.6 \pm 1.4 \mathrm{~g}$ /day for the CD group in comparison to $22.3 \pm 0.9 \mathrm{~g}$ /day in the control group. ${ }^{91} \mathrm{In}$ another study, high intakes of mono- and disaccharides, and total fats, consistently increased the risk for developing both forms of IBD. ${ }^{92}$ Linoleic acid has also been associated with an increased risk of UC (OR 2.49, 95\% CI 1.23-5.07 for the highest quartile). ${ }^{93}$ In a case control study of children published in 2008, a positive association with CD was found in girls with a diet rich in meats, fatty foods, and desserts (OR 4.7, 95\% CI 1.6-14.2); however, a diet of vegetables, fruits, olive oil, fish, grains, and nuts was inversely associated with $\mathrm{CD}$ in both genders (girls: OR 0.3, 95\% CI 0.1-0.9; boys: OR $0.2,95 \%$ CI $0.1-0.5) .{ }^{94}$ Although diet as a risk factor for $\mathrm{CD}$ has been studied extensively in the past, there is still a large gap in knowledge due to limitations of retrospective data collection and recall bias for dietary histories. ${ }^{95}$

\section{Stress and mood}

Stress has also been associated with IBD in the literature. Although studies have not been entirely consistent, it is believed that stress contributes not only to development of disease but also to disease exacerbations. In a case control study ${ }^{96}$ using univariate analysis, occurrence of stress through life events was found to be more frequent in the 6 month period prior to CD diagnosis when compared to control groups. However, after adjustment for depression and anxiety scores, as well as other characteristics such as smoking status and sociodemographic features, this association appeared to be nonsignificant. ${ }^{96}$ In a recent prospective study of women, depressive symptoms were associated with an increased risk of CD development (adjusted HR 2.39, 95\% CI 1.40-3.98), but not UC development. ${ }^{97}$ The proposed mechansims for the association between stress and IBD development are alteration in immune function, as well as physiologic changes in the gut mediated by the motor, sensory, and secretory effects of stress..$^{98}$ In particular, stress may increase intestinal permeability, potentially as a result of alterations in the cholinergic nervous system and mucosal mast cell function. ${ }^{98,99}$ Data revealing that psychological stress may increase inflammation and worsen the clinical course of immune-mediated inflammatory disease are also increasing. ${ }^{100} \mathrm{~A}$ recent study has shown that although shortterm stress does not trigger exacerbation in UC, long-term 


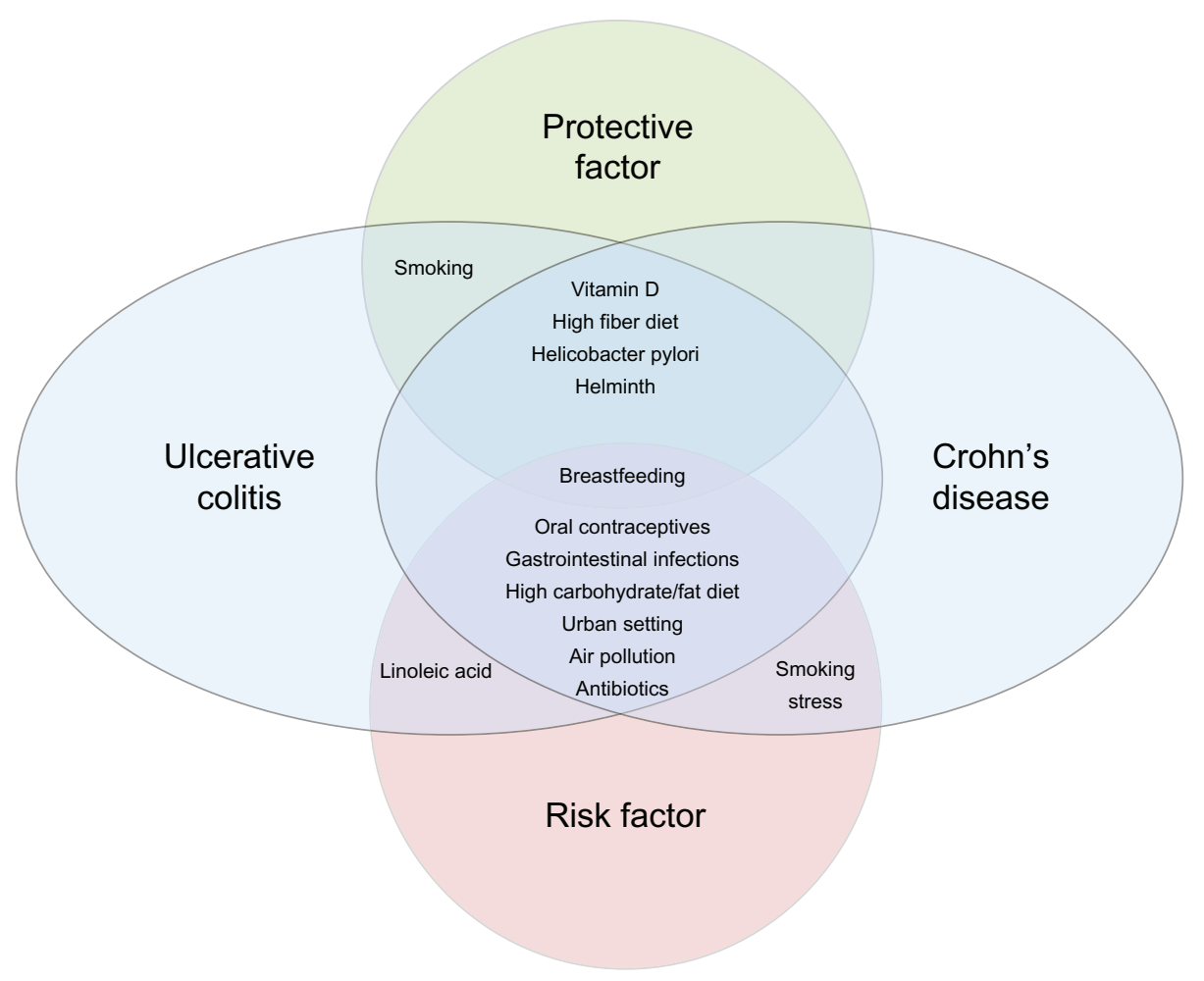

Figure I The relationship between environmental factors and development of Crohn's disease and ulcerative colitis.

perceived stress increases the risk of flare over a period of months to years. ${ }^{101}$ Furthermore, in a prospective population based study from Canada by Bernstein et al, perceived stress, negative affect (mood), and major life events were the only triggers significantly associated with flares of IBD. ${ }^{71}$ In a recent multi-institution cohort, mood or anxiety comorbidity was associated with a $28 \%$ increase in the risk of surgery in patients with $\mathrm{CD} .{ }^{102}$ Understanding the role of stress related comorbidities is important in the epidemiology of IBD, as treatment of these disorders may impact disease onset or course.

\section{Conclusion}

The epidemiology of IBD is evolving. The highest incidence rates of IBD are in Europe and North America, although the overall prevalence of both $\mathrm{CD}$ and $\mathrm{UC}$ is increasing throughout the world. In particular, disease is emerging in previously low prevalence areas, such as the developing world, and among emigrant populations moving to industrialized, westernized societies. These more recent changes in reported incidence and prevalence are likely due to (1) advances in disease detection and recognition, and (2) continued environmental alterations and exposures impacting IBD onset. The hygiene hypothesis is central to our understanding of environmental exposures and their impact on the immunologic response of the gut mucosa among those genetically susceptible to IBD. These interactions between environmental and genetic influences, and ultimately their effects on the microbiota, are influencing disease onset and course. Interestingly, both protective environmental factors and risk factors have been identified in many studies. Some factors may increase the risk for one disease subtype, while reducing the risk for the other. Figure 1 shows the complicated relationships between these various factors and CD or UC development, based on our current understanding of the limited evidence. Evidence thus far has primarily been retrospective, and subject to recall bias. Thus, better evidence is needed to enhance our understanding of IBD epidemiology. As IBD is a relatively rare disorder, with complicated interactions between potential inciting agents, very large cohorts with detailed, prospectively collected, environmental exposure data will be needed. Of equal importance, particularly to patients with established disease, is a better understanding of the effects of environmental exposures on disease course. Again, large, well-phenotyped cohorts of IBD patients are needed, with detailed prospective collection of environmental exposure data. Ultimately, our goal will be to use such data to design much needed preventative recommendations in those genetically at high risk for IBD, or among those with established disease to help to prevent 
relapse. Thus, further study in the ever evolving field of IBD epidemiology is warranted.

\section{Acknowledgment}

This work was supported in part by a career development award from the Crohn's and Colitis Foundation of America (ML).

\section{Disclosure}

The authors declare no conflict of interest in this work.

\section{References}

1. Molodecky NA, Soon IS, Rabi DM, et al. Increasing incidence and prevalence of the inflammatory bowel diseases with time, based on systematic review. Gastroenterology. 2012;142:46-54 e42; quiz e30.

2. Ng SC, Bernstein CN, Vatn MH, et al. Geographical variability and environmental risk factors in inflammatory bowel disease. Gut. 2013;62: 630-649.

3. Benchimol EI, Fortinsky KJ, Gozdyra P, Van den Heuvel M, Van Limbergen J, Griffiths AM. Epidemiology of pediatric inflammatory bowel disease: a systematic review of international trends. Inflamm Bowel Dis. 2011;17:423-439.

4. Loftus EV Jr. Clinical epidemiology of inflammatory bowel disease: Incidence, prevalence, and environmental influences. Gastroenterology. 2004;126:1504-1517.

5. Bernstein CN, Shanahan F. Disorders of a modern lifestyle: reconciling the epidemiology of inflammatory bowel diseases. Gut. 2008;57: 1185-1191.

6. Prideaux L, Kamm MA, De Cruz PP, Chan FK, Ng SC. Inflammatory bowel disease in Asia: a systematic review. $J$ Gastroenterol Hepatol. 2012;27:1266-1280.

7. Malmborg P, Grahnquist L, Lindholm J, Montgomery S, Hildebrand H. Increasing incidence of paediatric inflammatory bowel disease in Northern Stockholm County 2002-2007. J Pediatr Gastroenterol Nutr. Epub March 1, 2013.

8. Grieci T, Butter A. The incidence of inflammatory bowel disease in the pediatric population of Southwestern Ontario. J Pediatr Surg. 2009;44: 977-980.

9. Bernstein CN, Rawsthorne P, Cheang M, Blanchard JF. A populationbased case control study of potential risk factors for IBD. Am J Gastroenterol. 2006;101:993-1002.

10. Perminow G, Brackmann S, Lyckander LG, et al. A characterization in childhood inflammatory bowel disease, a new population-based inception cohort from South-Eastern Norway, 2005-2007, showing increased incidence in Crohn's disease. Scand J Gastroenterol. 2009;44:446-456.

11. Lehtinen $\mathrm{P}$, Ashorn $\mathrm{M}$, Iltanen $\mathrm{S}$, et al. Incidence trends of pediatric inflammatory bowel disease in Finland, 1987-2003, a nationwide study. Inflamm Bowel Dis. 2011;17:1778-1783.

12. Pinsk V, Lemberg DA, Grewal K, Barker CC, Schreiber RA, Jacobson K. Inflammatory bowel disease in the South Asian pediatric population of British Columbia. Am J Gastroenterol. 2007;102:1077-1083.

13. Probert CS, Jayanthi V, Pinder D, Wicks AC, Mayberry JF. Epidemiological study of ulcerative proctocolitis in Indian migrants and the indigenous population of Leicestershire. Gut. 1992;33:687-693.

14. Barreiro-de Acosta M, Alvarez Castro A, Souto R, Iglesias M, Lorenzo A, Dominguez-Munoz JE. Emigration to western industrialized countries: A risk factor for developing inflammatory bowel disease. J Crohns Colitis. 2011;5:566-569.

15. Benchimol EI, Guttmann A, Griffiths AM, et al. Increasing incidence of paediatric inflammatory bowel disease in Ontario, Canada: evidence from health administrative data. Gut. 2009;58:1490-1497.
16. Fleischer DE, Grimm IS, Friedman LS. Inflammatory bowel disease inolder patients. Med Clin North Am. 1994;78:1303-1319.

17. Grimm IS, Friedman LS. Inflammatory bowel disease in the elderly. Gastroenterol Clin North Am. 1990;19:361-389.

18. Lashner BA, Kirsner JB. Inflammatory bowel disease in older people. Clin Geriatr Med. 1991;7:287-299.

19. Lindner AE. Inflammatory bowel disease in the elderly. Clin Geriatr Med. 1999;15:487- 497

20. Robertson DJ, Grimm IS. Inflammatory bowel disease in the elderly. Gastroenterol Clin North Am. 2001;30:409-426.

21. Softley A, Myren J, Clamp SE, et al. Inflammatory bowel disease in the elderly patient. Scand J Gastroenterol Suppl. 1988;144:27-30.

22. Ananthakrishnan AN, Binion DG. Treatment of ulcerative colitis in the elderly. Dig Dis. 2009;27(3):327-334.

23. Katz S, Pardi DS. Inflammatory bowel disease of the elderly: frequently asked questions (FAQs). Am J Gastroenterol. 2011;106: 1889-1897.

24. Cho JH, Brant SR. Recent insights into the genetics of inflammatory bowel disease. Gastroenterology. 2011;140:1704-1712.

25. Denson LA, Long MD, McGovern DP, et al. Challenges in IBD Research: Update on Progress and Prioritization of the CCFA's Research Agenda. Inflamm Bowel Dis. 2013;19:677-682.

26. Halfvarson J, Bodin L, Tysk C, Lindberg E, Jarnerot G. Inflammatory bowel disease in a Swedish twin cohort: a long-term follow-up of concordance and clinical characteristics. Gastroenterology. 2003;124:1767-1773.

27. Brant SR. Update on the heritability of inflammatory bowel disease: the importance of twin studies. Inflamm Bowel Dis. 2011;17:1-5.

28. Halfvarson J. Genetics in twins with Crohn's disease: less pronounced than previously believed? Inflamm Bowel Dis. 2011;17:6-12.

29. Hugot JP, Cezard JP, Colombel JF, et al. Clustering of Crohn's disease within affected sibships. Eur J Hum Genet. 2003;11:179-184.

30. Laharie D, Debeugny S, Peeters M, et al. Inflammatory bowel disease in spouses and their offspring. Gastroenterology. 2001;120: 816-819.

31. Sartor RB. Microbial influences in inflammatory bowel diseases. Gastroenterology. 2008;134:577-594.

32. Olszak T, An D, Zeissig S, et al. Microbial exposure during early life has persistent effects on natural killer T cell function. Science. 2012;336: 489-493.

33. Round JL, Lee SM, Li J, et al. The Toll-like receptor 2 pathway establishes colonization by a commensal of the human microbiota. Science. 2011;332:974-977.

34. Atarashi K, Tanoue T, Shima T, et al. Induction of colonic regulatory T cells by indigenous Clostridium species. Science. 2011;331:337-341.

35. Hviid A, Svanstrom H, Frisch M. Antibiotic use and inflammatory bowel diseases in childhood. Gut. 2011;60:49-54.

36. Molodecky NA, Kaplan GG. Environmental risk factors for inflammatory bowel disease. Gastroenterol Hepatol (N Y). 2010;6:339-346.

37. Castiglione F, Diaferia M, Morace F, et al. Risk factors for inflammatory bowel diseases according to the "hygiene hypothesis": a case-control, multi-centre, prospective study in Southern Italy. J Crohns Colitis. 2012;6:324-329.

38. Baron S, Turck D, Leplat C, et al. Environmental risk factors in paediatric inflammatory bowel diseases: a population based case control study. Gut. 2005;54:357-363.

39. Klement E, Cohen RV, Boxman J, Joseph A, Reif S. Breastfeeding and risk of inflammatory bowel disease: a systematic review with meta-analysis. Am J Clin Nutr. 2004;80:1342-1352.

40. Barclay AR, Russell RK, Wilson ML, Gilmour WH, Satsangi J, Wilson DC. Systematic review: the role of breastfeeding in the development of pediatric inflammatory bowel disease. J Pediatr. 2009;155:421-426.

41. Khalili H, Ananthakrishnan AN, Higuchi LM, Richter JM, Fuchs CS, Chan AT. Early life factors and risk of inflammatory bowel disease in adulthood. Inflamm Bowel Dis. 2013;19:542-547.

42. Gearry RB, Richardson AK, Frampton CM, Dodgshun AJ, Barclay ML. Population-based cases control study of inflammatory bowel disease risk factors. J Gastroenterol Hepatol. 2010;25:325-333. 
43. Hansen TS, Jess T, Vind I, et al. Environmental factors in inflammatory bowel disease: a case-control study based on a Danish inception cohort. J Crohns Colitis. 2011;5:577-584.

44. Fanaro S, Chierici R, Guerrini P, Vigi V. Intestinal microflora in early infancy: composition and development. Acta Paediatr Suppl. 2003;91: $48-55$.

45. Midtvedt AC, Midtvedt T. Production of short chain fatty acids by the intestinal microflora during the first 2 years of human life. $J$ Pediatr Gastroenterol Nutr. 1992;15:395-403.

46. Gradel KO, Nielsen HL, Schonheyder HC, Ejlertsen T, Kristensen B, Nielsen H. Increased short- and long-term risk of inflammatory bowel disease after salmonella or campylobacter gastroenteritis. Gastroenterology. 2009;137:495-501.

47. Porter CK, Tribble DR, Aliaga PA, Halvorson HA, Riddle MS. Infectious gastroenteritis and risk of developing inflammatory bowel disease. Gastroenterology. 2008;135:781-786.

48. Luther J, Dave M, Higgins PD, Kao JY. Association between Helicobacter pylori infection and inflammatory bowel disease: a metaanalysis and systematic review of the literature. Inflamm Bowel Dis. 2010;16:1077-1084.

49. Ram M, Barzilai O, Shapira Y, et al. Helicobacter pylori serology in autoimmune diseases - fact or fiction? Clin Chem Lab Med. 2012;0: 1-8.

50. Sonnenberg A, Genta RM. Low prevalence of Helicobacter pylori infection among patients with inflammatory bowel disease. Aliment Pharmacol Ther. 2012;35:469-476.

51. Owyang SY, Luther J, Owyang CC, Zhang M, Kao JY. Helicobacter pylori DNA's anti-inflammatory effect on experimental colitis. Gut Microbes. 2012;3:168-171.

52. Elliott DE, Weinstock JV. Where are we on worms? Curr Opin Gastroenterol. 2012;28:551-556.

53. Hunter MM, McKay DM. Review article: helminths as therapeutic agents for inflammatory bowel disease. Aliment Pharmacol Ther. 2004; 19:167-177.

54. Chu KM, Watermeyer G, Shelly L, et al. Childhood helminth exposure is protective against inflammatory bowel disease: a case control study in South Africa. Inflamm Bowel Dis. 2013;19:614-620.

55. Blum AM, Hang L, Setiawan T, et al. Heligmosomoides polygyrus bakeri induces tolerogenic dendritic cells that block colitis and prevent antigen-specific gut T cell responses. J Immunol. 2012;189:2512-2520.

56. Walk ST, Blum AM, Ewing SA, Weinstock JV, Young VB. Alteration of the murine gut microbiota during infection with the parasitic helminth Heligmosomoides polygyrus. Inflamm Bowel Dis. 2010;16: 1841-1849.

57. Summers RW, Elliott DE, Urban JF Jr, Thompson R, Weinstock JV. Trichuris suis therapy in Crohn's disease. Gut. 2005;54:87-90.

58. Summers RW, Elliott DE, Urban JF Jr, Thompson RA, Weinstock JV. Trichuris suis therapy for active ulcerative colitis: a randomized controlled trial. Gastroenterology. 2005;128:825-832.

59. Kronman, M. P., Zaoutis, T. E., Haynes, K., Feng, R., Coffin, S. E. Antibiotic exposure and IBD development among children: a population-based cohort study. Pediatrics. 2012; 130:794-803.

60. Shaw SY, Blanchard JF, Bernstein CN. Association between the use of antibiotics in the first year of life and pediatric inflammatory bowel disease. Am J Gastroenterol. 2010;105:2687-2692.

61. Virta L, Auvinen A, Helenius H, Huovinen P, Kolho KL. Association of repeated exposure to antibiotics with the development of pediatric Crohn's disease - a nationwide, register-based finnish case-control study. Am J Epidemiol. 2012;175:775-784.

62. Shaw SY, Blanchard JF, Bernstein CN. Association between the use of antibiotics and new diagnoses of Crohn's disease and ulcerative colitis. Am J Gastroenterol. 2011;106:2133-2142.

63. Khalili H, Higuchi LM, Ananthakrishnan AN, et al. Oral contraceptives, reproductive factors and risk of inflammatory bowel disease. Gut. Epub June 1, 2012.

64. Cornish JA, Tan E, Simillis C, Clark SK, Teare J, Tekkis PP. The risk of oral contraceptives in the etiology of inflammatory bowel disease: a meta-analysis. Am J Gastroenterol. 2008;103:2394-2400.
65. Timmer, A. Sutherland, L. R. Martin, F. Oral contraceptive use and smoking are risk factors for relapse in Crohn's disease. The Canadian Mesalamine for Remission of Crohn's Disease Study Group. Gastroenterology. 1998;114:1143-1150.

66. Cosnes J, Carbonnel F, Carrat F, Beaugerie L, Gendre JP. Oral contraceptive use and the clinical course of Crohn's disease: a prospective cohort study. Gut. 1999;45:218-222.

67. Zapata LB, Paulen ME, Cansino C, Marchbanks PA, Curtis KM. Contraceptive use among women with inflammatory bowel disease: A systematic review. Contraception. 2010;82:72-85.

68. Cipolla G, Crema F, Sacco S, Moro E, de Ponti F, Frigo G. Nonsteroidal anti-inflammatory drugs and inflammatory bowel disease: current perspectives. Pharmacol Res. 2002;46:1-6.

69. Ananthakrishnan AN, Higuchi LM, Huang ES, et al. Aspirin, nonsteroidal anti-inflammatory drug use, and risk for Crohn disease and ulcerative colitis: a cohort study. Ann Intern Med. 2012;156:350-359.

70. Takeuchi K, Smale S, Premchand P, et al. Prevalence and mechanism of nonsteroidal anti-inflammatory drug-induced clinical relapse in patients with inflammatory bowel disease. Clin Gastroenterol Hepatol. 2006;4:196-202.

71. Bernstein CN, Singh S, Graff LA, Walker JR, Miller N, Cheang M. A prospective population-based study of triggers of symptomatic flares in IBD. Am J Gastroenterol. 2010;105:1994-2002.

72. De Silva P, Ananthakrishnan AN. Vitamin D and IBD: More pieces to the puzzle, still no complete picture. Inflamm Bowel Dis. 2012;18: 1391-1393.

73. Khalili H, Huang ES, Ananthakrishnan AN, et al. Geographical variation and incidence of inflammatory bowel disease among US women. Gut. 2012;61:1686-1692.

74. Ananthakrishnan AN, Khalili H, Higuchi LM, et al. Higher predicted vitamin D status is associated with reduced risk of Crohn's disease. Gastroenterology. 2012;142:482-489.

75. Ulitsky A, Ananthakrishnan AN, Naik A, et al. Vitamin D deficiency in patients with inflammatory bowel disease: association with disease activity and quality of life. JPEN J Parenter Enteral Nutr. 2011;35:308-316.

76. Soon IS, Molodecky NA, Rabi DM, Ghali WA, Barkema HW, Kaplan GG. The relationship between urban environment and the inflammatory bowel diseases: a systematic review and meta-analysis. BMC Gastroenterol. 2012;12:51.

77. Haug K, Schrumpf E, Halvorsen JF, et al. Epidemiology of Crohn's disease in western Norway. Study group of Inflammatory Bowel Disease in Western Norway. Scand J Gastroenterol. 1989;24:1271-1275.

78. Kaplan GG, Hubbard J, Korzenik J, et al. The inflammatory bowel diseases and ambient air pollution: a novel association. Am J Gastroenterol. 2010;105:2412-2419.

79. Ananthakrishnan AN, McGinley EL, Binion DG, Saeian K. Ambient air pollution correlates with hospitalizations for inflammatory bowel disease: an ecologic analysis. Inflamm Bowel Dis. 2011;17:1138-1145.

80. Sonnenberg A. Occupational distribution of inflammatory bowel disease among German employees. Gut. 1990;31:1037-1040.

81. Calkins BM. A meta-analysis of the role of smoking in inflammatory bowel disease. Dig Dis Sci. 1989;34:1841-1854.

82. Mahid SS, Minor KS, Soto RE, Hornung CA, Galandiuk S. Smoking and inflammatory bowel disease: a meta-analysis. Mayo Clin Proc. 2006;81:1462-1471.

83. Higuchi LM, Khalili H, Chan AT, Richter JM, Bousvaros A, Fuchs CS. A prospective study of cigarette smoking and the risk of inflammatory bowel disease in women. Am J Gastroenterol. 2012;107: 1399-1406.

84. Cosnes J. Tobacco and IBD: relevance in the understanding of disease mechanisms and clinical practice. Best Pract Res Clin Gastroenterol. 2004;18:481-496.

85. Cosnes J, Carbonnel F, Carrat F, Beaugerie L, Cattan S, Gendre J. Effects of current and former cigarette smoking on the clinical course of Crohn's disease. Aliment Pharmacol Ther. 1999;13:1403-1411.

86. Cosnes J. Smoking, physical activity, nutrition and lifestyle: environmental factors and their impact on IBD. Dig Dis. 2010;28:411-417. 
87. Leong RW, Lau JY, Sung JJ. The epidemiology and phenotype of Crohn's disease in the Chinese population. Inflamm Bowel Dis. 2004;10: 646-651.

88. Chapman-Kiddell CA, Davies PS, Gillen L, Radford-Smith GL. Role of diet in the development of inflammatory bowel disease. Inflamm Bowel Dis. 2010;16:137-151.

89. Zallot C, Quilliot D, Chevaux JB, et al. Dietary beliefs and behavior among inflammatory bowel disease patients. Inflamm Bowel Dis. 2013;19:66-72.

90. Silkoff K, Hallak A, Yegena L, et al. Consumption of refined carbohydrate by patients with Crohn's disease in Tel-Aviv-Yafo. Postgrad Med J. 1980;56:842-846.

91. Kasper H, Sommer H. Dietary fiber and nutrient intake in Crohn's disease. Am J Clin Nutr. 1979;32:1898-1901.

92. Gentschew L, Ferguson LR. Role of nutrition and microbiota in susceptibility to inflammatory bowel diseases. Mol Nutr Food Res. 2012;56: 524-535.

93. Tjonneland A, Overvad K, Bergmann MM, et al. Linoleic acid, a dietary n-6 polyunsaturated fatty acid, and the aetiology of ulcerative colitis: a nested case-control study within a European prospective cohort study. Gut. 2009;58:1606-1611.

94. D’Souza S, Levy E, Mack D, et al. Dietary patterns and risk for Crohn's disease in children. Inflamm Bowel Dis. 2008;14:367-373.
95. Ananthakrishnan AN. Environmental triggers for inflammatory bowel disease. Curr Gastroenterol Rep. 2013;15:302.

96. Lerebours E, Gower-Rousseau C, Merle V, et al. Stressful life events as a risk factor for inflammatory bowel disease onset: A populationbased case-control study. Am J Gastroenterol. 2007;102:122-131.

97. Ananthakrishnan AN, Khalili H, Pan A, et al. Association between depressive symptoms and incidence of Crohn's disease and ulcerative colitis: results from the Nurses' Health Study. Clin Gastroenterol Hepatol. 2013;11:57-62

98. Sajadinejad MS, Asgari K, Molavi H, Kalantari M, Adibi P. Psychological issues in inflammatory bowel disease: an overview. Gastroenterol Res Pract. 2012;2012:106502.

99. Hollander D. Inflammatory bowel diseases and brain-gut axis. J Physiol Pharmacol. 2003;54 Suppl 4:183-190.

100. Rampton DS. The influence of stress on the development and severity of immune-mediated diseases. J Rheumatol Suppl. 2011;88:43-47.

101. Levenstein S, Prantera C, Varvo V, et al. Stress and exacerbation in ulcerative colitis: a prospective study of patients enrolled in remission. Am J Gastroenterol. 2000;95:1213-1220.

102. Ananthakrishnan AN, Gainer VS, Perez RG, et al. Psychiatric co-morbidity is associated with increased risk of surgery in Crohn's disease. Aliment Pharmacol Ther. 2013;37:445-454.
Clinical Epidemiology

\section{Publish your work in this journal}

Clinical Epidemiology is an international, peer-reviewed, open access journal focusing on disease and drug epidemiology, identification of risk factors and screening procedures to develop optimal preventative initiatives and programs. Specific topics include: diagnosis, prognosis, treatment, screening, prevention, risk factor modification, systematic

Submit your manuscript here: http://www.dovepress.com/clinical-epidemiology-journal

\section{Dovepress}

reviews, risk \& safety of medical interventions, epidemiology \& biostatical methods, evaluation of guidelines, translational medicine, health policies \& economic evaluations. The manuscript management system is completely online and includes a very quick and fair peer-review system, which is all easy to use. 